Revista Brasileira de Agricultura Irrigada v.8, nº. 5, p.375 - 390, 2014

ISSN 1982-7679 (On-line)

Fortaleza, CE, INOVAGRI - http://www.inovagri.org.br

DOI: $10.7127 /$ rbai.v8n500245

Protocolo 245.14 - 26/04/2014 Aprovado em 05/08/2014

\title{
CARACTERÍSTICAS FÍSICO-HÍDRICAS DE UM LATOSSOLO SOB DIFERENTES SISTEMAS DE MANEJO
}

Nelmício Furtado da Silva ${ }^{1}$, Fernando Nobre $\mathrm{Cunha}^{2}$, Renato Campos de Oliveira ${ }^{3}$, Fernando Rodrigues Cabral Filho ${ }^{4}$; Marconi Batista Teixeira ${ }^{5}$ José Joaquim Carvalho $^{6}$

\section{RESUMO}

A expansão da agricultura no cerrado vem afetando prejudicialmente às propriedades físicas do solo. Sendo agravado pelo manejo inapropriado e uso inadequado do solo, onde não são levadas em consideração suas características físicas para implantação do sistema de cultivo. Objetivou-se nesse trabalho observar o impacto da agricultura nos solos do sudoeste goiano, demonstrando os estágios de degradação de solos sob diferentes condições de uso antrópico. As áreas estudadas localizam-se no Instituto Federal Goiano - Câmpus Rio Verde, GO. O solo da região foi classificado como Latossolo Vermelho distroférrico (LVdf). Foram avaliados o manejo de quatro áreas distintas: cultivo de cana-de-açúcar primeiro ano; plantio convencional de culturas anuais (soja/milho); ILPF (3 anos) e área de Cerrado permanente. Foram determinadas as curvas de velocidade de infiltração (VI), velocidade de infiltração básica (VIB), condutividade hidráulica (Kfs), densidade do solo (Ds), macroporosidade (Macro), microporosidade (Micro), porosidade total (PT), densidade de partículas (Dp). O sistema manejado com cana obteve as condições de solo favoráveis principalmente em relação a Ds, Dp, PT e Macro de 0 a $20 \mathrm{~cm}$ e PT de 20 a $40 \mathrm{~cm}$. O cerrado por manter as suas caracterizas do solo, apresentou o maior valor de VIB $\left(56,89 \mathrm{~cm} \mathrm{~h}^{-1}\right)$. Em médio prazo, o intenso sistema de preparo do solo mostrou-se mais correlacionado com a capacidade do solo de infiltração do que o próprio processo de compactação em si.

Palavras-chave: infiltração, compactação, atributos físicos, interferência antrópica.

\section{WATER-PHYSICAL CHARACTERISTICS OF A LATOSOL UNDER DIFFERENT MANAGEMENT SYSTEMS}

\footnotetext{
${ }^{1}$ Mestrando em Ciências Agrárias - Agronomia, Instituto Federal Goiano - Câmpus Rio Verde, Rodovia Sul Goiana, Km 01, CEP: 75.901-170, Rio Verde - GO, e-mail: nelmiciofurtado@ gmail.com

${ }^{2}$ Mestrando em Ciências Agrárias - Agronomia, IFGoiano - Câmpus Rio Verde, e-mail: fernandonobrecunha@hotmail.com

${ }^{3}$ Acadêmico de agronomia, IFGoiano - Câmpus Rio Verde, e-mail: renatocoagro@gmail.com

${ }^{4}$ Acadêmico de agronomia, IFGoiano - Câmpus Rio Verde, e-mail: fernandorcfilho10@ gmail.com .

${ }^{5}$ Eng. Agrônomo, Prof. Dr. em Agronomia, IFGoiano - Câmpus Rio Verde, e-mail: marconibt@ gmail.com

6 Pós-Doutorando em Ciências Agrárias - Agronomia, IFGoiano - Câmpus Rio Verde, e-mail: josejoaquimcarvalho@yahoo.com.br
} 


\begin{abstract}
The expansion of agriculture in the cerrado is adversely affecting the physical properties of the soil. Being compounded by inappropriate management and inadequate soil, where they are not taken into account their physical characteristics to implement the cropping system. The objective of this work to observe the impact of agriculture on soils of southwest of Goias State, showing the stages of degradation of soils under different anthropogenic use. The areas studied are located in Goiás Federal Institute - Campus Rio Verde - GO. The soil in the area was classified as dystrophic Oxisol. Managing four different areas were evaluated: cultivation of sugarcane (3 year); conventional planting annual crops (soya/corn); ILPF (3 years) and Cerrado area permanent reserve. We determined the rate of infiltration curves (VI), infiltration rate (VIB), hydraulic conductivity (Kfs), soil density (Ds), macroporosity (Macro) and microporosity (Micro), the total porosity (TP), density particles (Dp). The system managed sugarcane obtained with favorable soil conditions mainly to the Ds, Dp, PT and Macro 0 to $20 \mathrm{~cm}$ and 20 to $40 \mathrm{~cm}$. The Cerrado to keep you characterize their soil showed the highest VIB $\left(56.89 \mathrm{~cm} \mathrm{~h}^{-1}\right)$. In the medium term, intensive tillage system was more correlated with soil infiltration capacity than the compaction process itself.
\end{abstract}

Keywords: infiltration, compression, physical attributes, human interference.

\section{INTRODUÇÃO}

A expansão da agricultura no cerrado ao longo dos anos vem afetando prejudicialmente às propriedades físicas, químicas e biológicas do solo. Esse fato é agravado pelo manejo inapropriado e uso inadequado do solo, onde não são levadas em consideração suas características físicas para implantação do sistema de cultivo. $\mathrm{O}$ manejo inadequado causa a compactação do solo, redução na absorção de nutrientes, alteração na infiltração e redistribuição de água e redução da condutividade hidráulica. A adoção de sistemas de manejo que mantém ou melhoram a qualidade do solo tem-se apresentado como uma alternativa viável no sistema produtivo agrícola.

Segundo José et al. (2012) o conhecimento da variabilidade das variáveis físico-hídricas do solo, no espaço e no tempo, é considerado, atualmente, o princípio básico para o manejo preciso das áreas agrícolas. Uma importante função do solo, influenciada pela porosidade, é a transmissão de água, que afeta diretamente a produtividade das plantas e o ambiente (GONÇALVES \& MORAES, 2012).
Os diferentes sistemas de manejo de solos têm a finalidade de reduzir essas restrições, propiciando condições favoráveis ao desenvolvimento das culturas (PRANDO et al., 2010). O processo de infiltração da água no solo é um parâmetro importante a ser monitorado em áreas de irrigação, seja a velocidade de infiltração (VI) ou a velocidade de infiltração básica (VIB) possibilitam determinar o tempo de irrigação, para métodos de irrigação por superfície. O processo de infiltração, porém é influenciado por diversos fatores, como o tipo de solo, a água já existente no solo, (umidade do solo) quantidade de chuva ou irrigação, matéria orgânica e a variabilidade espacial do terreno, topografia, cobertura vegetal, sistema radicular, atividade biológica, rugosidade superficial, agregação do solo (densidade do solo e de partículas), porosidade (ALVES SOBRINHO, et al., 2003; PANACHUKI, et al., 2006). A agregação e porosidade do solo são fatores importantes, pois podem modificar ao longo do tempo. A análise do solo a partir de amostras indeformadas comum é uma importante ferramenta para 
caracterização da estrutura do solo, uma vez que essa influencia várias de suas funções, e uma delas é a infiltração de água. Vale ressaltar que a relação entre o manejo e a qualidade do solo pode ser avaliada pelo comportamento das propriedades físicas, químicas e biológicas do solo. Além disso, o monitoramento da qualidade do solo pelos atributos físico-hídricos é importante para a manutenção e avaliação da sustentabilidade dos sistemas agrícolas.

Dessa forma, objetivou-se nesse trabalho observar o impacto da agricultura nos solos do sudoeste goiano, demonstrando os estágios de degradação de solos sob diferentes condições de uso antrópico.

\section{MATERIAIS E MÉTODOS}

O estudo foi realizado em áreas localizadas no Instituto Federal Goiano, em 2011, Câmpus

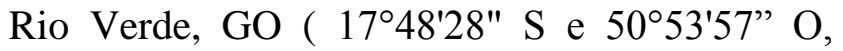
altitude média de 720 metros e relevo suave ondulado - $6 \%$ de declividade). O clima da região é classificado conforme Köppen, como Aw (tropical), com chuva nos meses de outubro a maio, e com seca de junho a setembro. A temperatura média anual é de 20 a $35{ }^{\circ} \mathrm{C}$ e as precipitações variam de 1.500 a $1.800 \mathrm{~mm}$ anuais. O solo predominante das áreas de estudo é classificado como Latossolo Vermelho distroférrico (LVdf) de textura média (EMBRAPA, 2006).

Em cada área experimental foi demarcada uma parcela, onde foram realizados os ensaios de campo para avaliação dos atributos submetidos a diferentes manejos. Assim foram selecionados 4 tratamentos, a saber: 1) Integração LavouraPecuária-Floresta - ILPF: Consorcio de capim (Brachiaria decumbens) com milho e Eucalipto (3 anos de implantação) com pisoteio de animais; 2) Cana: cultura de cana-de-açúcar cana-soca (2 anos de implantação); 3) Culturas
Anuais: sucessão (soja/milho) em sistema de plantio convencional e; 4) Cerrado: área de preservação (nativa).

Para as determinações de umidade do solo, foram coletadas amostras deformadas antes de cada teste de infiltração no campo, com auxílio de um trado, que foram submetidas ao laboratório de análise de solo, para determinação de umidade inicial, pelo método padrão de estufa. As amostras foram retiradas nas profundidades de 0 a 20; 20 a $40 \mathrm{~cm}$. Para as determinações físicas do solo foram coletadas amostras indeformadas, coletadas em anéis de Uhland de 6,34 $\mathrm{cm}$ de diâmetro e $5 \mathrm{~cm}$ de altura, nas profundidades de 0 a 20 e 20 a $40 \mathrm{~cm}$, que foram submetidas ao laboratório de análise de solo, para determinações físicas como: densidade do solo (Ds) foi determinada utilizando o método do anel volumétrico conforme Embrapa (1997); densidade de partículas (Dp) foi determinada utilizando-se água destilada e eliminação à vácuo do ar do picnômetro de acordo com Blake \& Hartge (1986); porosidade total (PT) foi obtida a partir dos valores da densidade do solo (Ds); e densidade de partículas (Dp), através da equação proposta por Vomocil (1965):

$$
P T=1-(D s / D p)
$$

A microporosidade foi determinada pela metodologia da Embrapa (1997), considerando o conteúdo de água retido no potencial matricial de $6 \mathrm{kPa}$. A macroporosidade foi calculada com base na diferença entre porosidade total e microporosidade.

Os testes de infiltração de água no solo foram realizados em cada um dos locais de estudo. A metodologia utilizada foi a do infiltrômetro de anéis concêntricos, de acordo com Bernardo (1989), constituído de um anel externo com $20 \mathrm{~cm}$ de diâmetro e $40 \mathrm{~cm}$ de altura e um anel interno com $10 \mathrm{~cm}$ de diâmetro e $40 \mathrm{~cm}$ de altura. $\mathrm{O}$ cilindro foi inserido no solo a uma profundidade de aproximadamente $20 \mathrm{~cm}$, 
com uma régua fixada na borda do cilindro interno, projetada até tocar a superfície do solo, para medir a lâmina de água. Os tempos em minutos de cada leitura foram: $0,1,2,5,10,15 \mathrm{e}$ 30 minutos a contar do instante zero e com repetições a cada 30 minutos até o tempo total de duração de cada teste de 210 minutos.

Os testes foram realizados até que a taxa de infiltração, observada no anel interno, tornase aproximadamente constante com o tempo. $\mathrm{O}$ critério adotado neste trabalho para condição de taxa de infiltração constante foi quando o valor de leitura da carga de água (hidráulica) no cilindro interno se repetiu pelo menos três vezes.

Foram determinadas as curvas de infiltração acumulada e velocidade de infiltração de água no solo e a condutividade hidráulica do solo saturado (Kfs) para descrever o volume de água que penetra no solo em função do tempo, através das seguintes equações:

$$
\begin{aligned}
& I=a T^{n} \\
& V=V_{0} T^{b}
\end{aligned}
$$

em que:

$I$ = infiltração acumulada, em mm;

$V=$ velocidade de infiltração de água no solo pelo método de Kostiakov, em $\mathrm{mm} \mathrm{ha}^{-1}$;

$a$ e $n=$ constantes que dependem do solo (adimensionais).

Foram determinadas as curvas de infiltração acumulada e de velocidade de infiltração de água no solo que descreve o volume de água que penetra no solo em função do tempo, através das seguintes equações:

$$
K_{0}=\frac{Q}{\left(\frac{\mathrm{H}+\mathrm{Z}_{w}}{Z_{w}}\right) A x T}
$$

em que:

$\mathrm{K}_{0}=$ Condutividade hidráulica saturada de campo $\left(\mathrm{m} \mathrm{h}^{-1}\right)$;

$\mathrm{Z}_{\mathrm{W}}=$ Profundidade da frente de saturação(m); $\mathrm{A}=$ Área da seção do anel $\left(\mathrm{m}^{2}\right)$;
$\mathrm{T}=$ Tempo entre duas leituras $(\mathrm{H})$;

$\mathrm{Q}=$ Volume de água infiltrada $\left(\mathrm{m}^{3}\right)$;

$\mathrm{H}=$ profundidade da água do anel, quando é ensaiada a regime constante $(\mathrm{m})$.

O delineamento experimental utilizado foi inteiramente casualizado com 4 repetições totalizando 12 testes de infiltração considerando os diferentes sistemas de uso do solo.

A análise estatística foi realizada com os parâmetros das fórmulas que representam a curva de infiltração de água no solo e velocidade de infiltração de água no solo. A umidade inicial do solo; a condutividade hidráulica e os parâmetros físicos do solo determinados obtidos para cada área em estudo foram comparados entre si pelo teste Tukey a 0,05 de probabilidade. O padrão espacial das variáveis físicas estudadas permitiu a elaboração dos mapas de distribuição espacial utilizando-se o software Surfer 9.0 (GOLDEN SOFTWARE, 2002).

\section{RESULTADOS E DISCUSSÃO}

Os valores dos atributos necessários à caracterização física do solo nos diferentes sistemas de manejo encontram- se na Tabela 1.

A cana de açúcar apresentou valores de atributos físicos do solo superiores para a maioria das características analisadas na profundidade de 0 a $20 \mathrm{~cm}$ como Ds, Dp e PT, porém para Macro não houve diferença dentre as áreas de estudo e em relação a Micro a área da cana de açúcar não se difere do Cerrado. Para a camada de 20 a $40 \mathrm{~cm}$, nas mesmas características verificadas, somente a cana de açúcar apresentou diferença dos outros tratamentos em relação a PT.

Também e possível observar em relação aos outros tratamentos quando comparados com Cerrado que a área manejada com Culturas Anuais difere em relação a Ds e PT na profundidade de 0 a $20 \mathrm{~cm}$ e PT de 20 a $40 \mathrm{~cm}$, assim como a Cana. Já a ILPF pouco se difere do 
Cerrado somente na profundidade de 0 a $20 \mathrm{~cm}$ para Dp e PT. Isso era esperado devido ao fato dessa área estar ocupada há muitos anos com ILPF e não sofrer um processo de revolvimento do solo principalmente em camadas mais profundas em relação as outras áreas de cultivo, além disso o processo de mecanização do solo para implantação deste sistema não é homogêneo em toda área dessa forma a amostragem feita ao acaso falharia em apresentar as variações encontradas e esconderia uma variação que existe e deve ser considerada. Souza et al. (2006), observaram que os sistemas de uso com cana-deaçúcar aumentaram a densidade do solo até a profundidade de $0,4 \mathrm{~m}$ em relação à mata nativa. Já a porosidade total e a macroporosidade do solo sob mata nativa foram superiores em todas as profundidades.

Tabela 1. Comparação das médias das características (Ds) Densidade do solo $\left(\mathrm{g} \mathrm{cm}^{-3}\right)$; (Dp) Densidade de partículas $\left(\mathrm{g} \mathrm{cm}^{-3}\right)$; (PT) Porosidade Total (\%); Macroporosidade (\%) e Microporosidade (\%) nas camadas de 0 a 20 e de 20 a $40 \mathrm{~cm}$.

\begin{tabular}{|c|c|c|c|c|c|}
\hline \multirow{2}{*}{$\begin{array}{c}\text { Sistema } \\
\text { de uso }\end{array}$} & Ds & $\mathrm{Dp}$ & PT & Macro & Micro \\
\hline & ------- & . & --- & $\%$ & ------ \\
\hline
\end{tabular}

$$
0-20 \mathrm{~cm}
$$

\begin{tabular}{cccccc} 
Cana & $0,9803 \mathrm{c}$ & $2,7876 \mathrm{a}$ & $0,6481 \mathrm{a}$ & $0,153 \mathrm{a}$ & $0,4949 \mathrm{a}$ \\
C. Anuais & $1,2574 \mathrm{a}$ & $2,6609 \mathrm{bc}$ & $0,5266 \mathrm{c}$ & $0,158 \mathrm{a}$ & $0,3677 \mathrm{~b}$ \\
ILPF & $1,2214 \mathrm{ab}$ & $2,5896 \mathrm{c}$ & $0,5281 \mathrm{c}$ & $0,135 \mathrm{a}$ & $0,3928 \mathrm{~b}$ \\
Cerrado & $1,1646 \mathrm{~b}$ & $2,6758 \mathrm{~b}$ & $0,5647 \mathrm{~b}$ & $0,136 \mathrm{a}$ & $0,4283 \mathrm{ab}$ \\
\hline
\end{tabular}

$$
20-40 \mathrm{~cm}
$$

$\begin{array}{cccccc}\text { Cana } & 0,966 \mathrm{a} & 2,74 \mathrm{ab} & 0,66 \mathrm{a} & 0,194 \mathrm{a} & 0,464 \mathrm{a} \\ \text { C. Anuais } & 1,290 \mathrm{a} & 2,72 \mathrm{ab} & 0,50 \mathrm{c} & 0,129 \mathrm{a} & 0,372 \mathrm{a} \\ \text { ILPF } & 1,249 \mathrm{a} & 2,62 \mathrm{~b} & 0,51 \mathrm{bc} & 0,182 \mathrm{a} & 0,330 \mathrm{a} \\ \text { Cerrado } & 1,190 \mathrm{a} & 2,68 \mathrm{ab} & 0,55 \mathrm{bc} & 0,134 \mathrm{a} & 0,417 \mathrm{a}\end{array}$

*Médias seguidas de mesma letra nas colunas não diferem entre si pelo teste Tukey a 5\% de probabilidade.
Observa-se na Figura 2 uma diminuição da velocidade de infiltração, assim como o aumento da taxa de infiltração acumulada ao longo do processo, até os valores se aproximarem de uma estabilidade, o que nesse caso, se encontra em $26,84 \mathrm{~cm} \mathrm{~h}^{-1}$ para Cana, $6,18 \mathrm{~cm} \mathrm{~h}^{-1} \mathrm{C}$. Anuais, $12,28 \mathrm{~cm} \mathrm{~h}^{-1}$ ILPF e $56,89 \mathrm{~cm} \mathrm{~h}^{-1}$ Cerrado, valores que de acordo com Bernardo et al. (2008) se enquadra em uma velocidade de infiltração básica muito alta (maior que $3 \mathrm{~cm} \mathrm{~h}^{-1}$ ). Apesar dos sistemas de manejo apresentarem uma VIB elevada apresentaram uma diferença significativa. Desta forma e possível ver que o Cerrado apresentou a maior média seguido por cana-de-açúcar, ILPF e C. Anuais. Os fatores que influenciam na velocidade de infiltração são: os materiais de superfície, cobertura vegetal, topografia, porosidade, matéria orgânica e o uso da terra com seus respectivos manejos (PEREIRA \& TEIXEIRA FILHO, 2009).

O cerrado por não sofrer nenhuma ação antrópica possui todas estas características "intactas", é muito superior aos outros sistema de manejo., Porém, dentre os tratamentos com cultivo agrícola, a velocidade de infiltração de água no solo foi maior nos tratamentos com maior revolvimento do solo o como é o caso do manejo para o cultivo da cana de açúcar que além de remover o solo mais profundamente, durante o período de cultivo este solo não volta a sofrer processo de revolvimento, apenas de compactação em função da colheita.

Já na pastagem ocorre uma série de processos para preparo e implantação do sistema, porém assim como na Cana durante o desenvolvimento o solo fica em repouso sem sofrer revolvimento, apesar de existir o pisoteio animal.

O caso mais extremo foi observado no sistema com C. Anuais que apesar de haver uma rotação de culturas que promove uma ação das raízes permitindo um aumento da infiltração de água no solo todo esse processo e muito superficial e, facilmente desfeito pelo fato de as culturas serem de ciclo anual. O processo de 
mecanização desse solo na camada mais superficial é intenso quebrando a ligação dos macroporos entre as duas camadas de solo, não há um tempo suficiente para que ocorra esta ligação dos poros entre as camadas o que contribui para uma diminuição da capacidade de infiltração deste solo, além de sofrer processo de compactação nos tratos culturais e na colheita.

Souza \& Alves (2003) mencionam que o preparo do solo, uma das principais operações de seu manejo, objetiva, entre outros, criar condições favoráveis ao crescimento e desenvolvimento das culturas, erradicar plantas invasoras e manejar resíduos culturais, aumentando a porosidade total na camada preparada. No entanto, seu principal efeito é refletido na perda da qualidade da estrutura do solo. Analisando a Figura 2, nos quatro sistemas de cultivo, observamos que na área de $\mathrm{C}$. Anuais, Atribui-se este processo à menor taxa de cobertura do solo, visto que, de acordo com Barcelos et al. (1999), os restos culturais sobre a superfície do solo interceptam e dissipam a energia cinética da chuva e do escoamento superficial, diminuindo a desagregação e o transporte de partículas. Isso ocorre principalmente quando o preparo é executado com excessiva intensidade e em solo com condições inadequadas de umidade, levando à sua compactação (ALVES et al., 2007) selamento superficial, diminuindo a velocidade de escoamento, aumentando o tempo de contato da água com o solo e permitindo, portanto, maior infiltração de água no solo. Segundo Paixão et al. (2009), o conhecimento da taxa de infiltração da água no solo é fundamental para definir técnicas de conservação do solo, planejar e dimensionar sistemas de irrigação e drenagem, bem como auxiliar na composição de uma imagem mais real da retenção da água e aeração do solo.

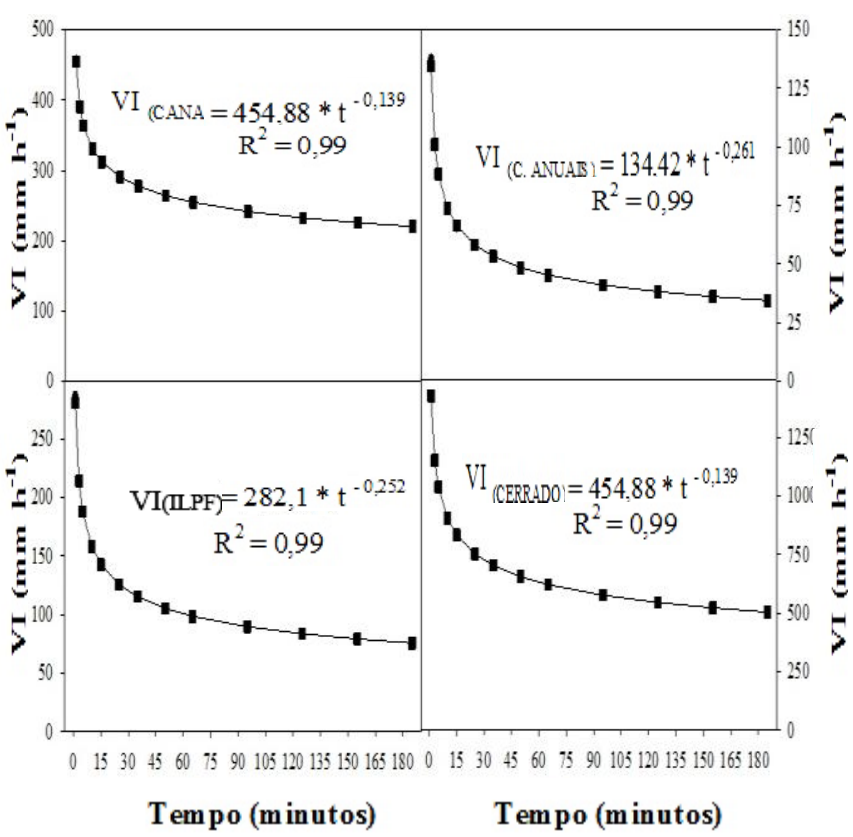

Figura 2. Velocidade de infiltração de água do Latossolo Vermelho distroférrico em função de diferentes usos do solo.

Os valores médios observados para umidade inicial do solo estão apresentados na Tabela 2.

A umidade inicial do solo apresentou valores muito próximos nas duas profundidades coletadas, como o teste de infiltração foi realizado no início do período chuvoso da região, o solo estava com baixa umidade, fazendo com que a VI demorasse a se estabilizar. Este processo é influenciado pelo conteúdo inicial de água do solo, condutividade hidráulica e características da camada superficial do solo, além de ser afetada também pela presença de camadas de baixa permeabilidade e duração da precipitação ou irrigação (BERNARDO, 2002). Segundo Panachuki (2003) a magnitude da infiltração é severamente reduzida pela formação ou presença do selamento superficial, fenômeno motivado pela pequena porosidade desta camada e à dominância de poros de pequeno diâmetro. 
Tabela 2. Comparação das médias das características Umidade do solo (g) em função dos tratamentos.

\begin{tabular}{ccccc}
\hline \multirow{2}{*}{$\begin{array}{c}\text { Profundidades } \\
(\mathrm{cm})\end{array}$} & Cana & C. Anuais & ILPF & Cerrado \\
\cline { 2 - 5 } & \multicolumn{4}{c}{ Umidade inicial do solo $(\mathrm{g})$} \\
\hline $0-20$ & $6,25 \mathrm{Aa}$ & $5,54 \mathrm{Bb}$ & $6,50 \mathrm{Ba}$ & $5,74 \mathrm{Bb}$ \\
$20-40$ & $6,12 \mathrm{Ac}$ & $7,18 \mathrm{Ab}$ & $8,43 \mathrm{Aa}$ & $7,35 \mathrm{Ab}$ \\
\hline
\end{tabular}

*Média com a mesma letra minúscula na linha $\mathrm{e}$ maiúsculas na coluna não indica diferença significativa pelo teste Tukey, a 5\% de probabilidade.

Os valores de condutividade hidráulica do solo saturado (Kfs) encontram-se na Tabela 4. Observa-se que o sistema Cerrado apresentou os maiores valores para o $\mathrm{Kfs}$, na profundidade estudada, diferindo estatisticamente dos demais sistemas de manejo. Os sistemas de cultivo Cana e ILPF mostraram valores intermediários, mas o sistema de C. Anuais, indicou os menores valores para a avaliação em questão.

Tabela 3. Comparação das médias das características (Kfs) Condutividade hidráulica do solo saturado $\left(\mathrm{m} \mathrm{h}^{-1}\right)$ em função dos tratamentos.

\begin{tabular}{ccccc}
\hline \multirow{2}{*}{$\begin{array}{c}\text { Profundidades } \\
(\mathrm{cm})\end{array}$} & \begin{tabular}{c} 
Cana \\
\cline { 2 - 4 }
\end{tabular} & C. Anuais & ILPF & Cerrado \\
\hline & \multicolumn{4}{c}{$\begin{array}{c}\text { Kfs) } \\
\text { saturado }\end{array}$} \\
\hline $0-40$ & $32,9 \mathrm{~b}$ & $5,35 \mathrm{~b}$ & $10,01 \mathrm{~b}$ & $174,67 \mathrm{a}$
\end{tabular}

*Média com a mesma letra na linha não indica diferença significativa pelo teste Tukey, a 5\% de probabilidade.

Confirma-se, dessa maneira, a importância da manutenção da cobertura do solo com quantidades elevadas de resíduo vegetal para preservar as propriedades físicas e impedir a formação de selamento superficial, que é uma das principais causas da diminuição da infiltração de água no solo (PANACHUKI, 2008). De maneira geral, pode-se considerar que os tratamentos caracterizados com maior intensidade de mecanização em períodos curtos onde não se consegue um tempo de reestruturação do solo tenderam a ser menos eficientes no processo de infiltração de água. Tais resultados são, contudo, justificáveis e aceitáveis. Evidenciam a variabilidades dos atributos dos solos e a necessidade de pesquisas aplicadas de forma a obter limites referenciais de valores aceitáveis para aplicação nos diversos campos de estudo.

Em linhas gerais, constatou-se variabilidade espacial considerável na área amostrada, evidenciando, inclusive, que os Latossolos, apesar de serem definidos como solos relativamente estáveis no ambiente, apresentam variação espacial de seus caracteres. Mesmo para as situações em que não houve diferença significativa entre as médias dos tratamentos, observou-se uma tendência de maior infiltração de água para os tratamentos com os menores valores de densidade do solo na camada de 0 a $20 \mathrm{~cm}$ do solo.

Para a variável Ds observa-se na Figura 3 que apenas na área da Cana não se obteve valores menores de Ds nas camadas superficiais do solo com relação as mais profundas, nota-se que o maior valor obtido encontra-se na camada de $20-25 \mathrm{~cm}$, sendo $1,09 \mathrm{~g} \mathrm{~cm}^{-3}$, porém na camada de $0-20 \mathrm{~cm}$ concentra-se os valores médios mais altos. $\mathrm{O}$ maior valor encontrado corresponde a um acréscimo de $22 \%$ comparando-se ao menor valor de $0,89 \mathrm{~g} \mathrm{~cm}^{-3}$ encontrado na camada mais profunda avaliada $(40 \mathrm{~cm})$. As demais áreas obtiveram valores de Ds menores nas camadas superficiais do solo (0 $-25 \mathrm{~cm}$ ), e maiores nas camadas mais profundas de solo $(25-40 \mathrm{~cm})$, com exceção da área de Cerrado, onde as menores Ds concentraram-se apenas na camada de $0-5 \mathrm{~cm}$, sendo que o centímetro inicial do solo obteve um decréscimo de $7 \%$ na Ds, com relação a parcela de solo entre $20-25 \mathrm{~cm}$ de profundidade onde encontrou-se a maior densidade do solo. Pode-se observar com bastante clareza na área de C. Anuais, onde nas camadas mais superficiais, correspondentes entre $5-20 \mathrm{~cm}$, decréscimo de $8 \%$ no valor obtido com relação ao maior $\left(1,31 \mathrm{~g} \mathrm{~cm}^{-3}\right)$ na camada de $40 \mathrm{~cm}$ do solo (Figura 3 ). 
Silva et al.
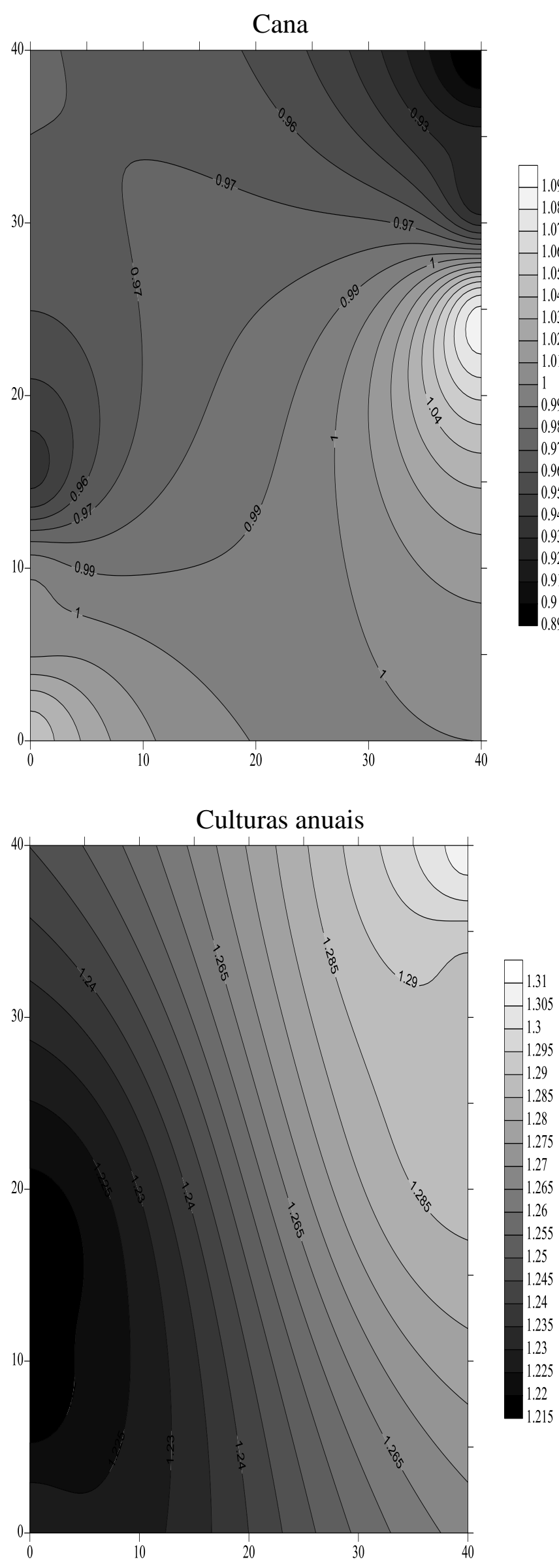
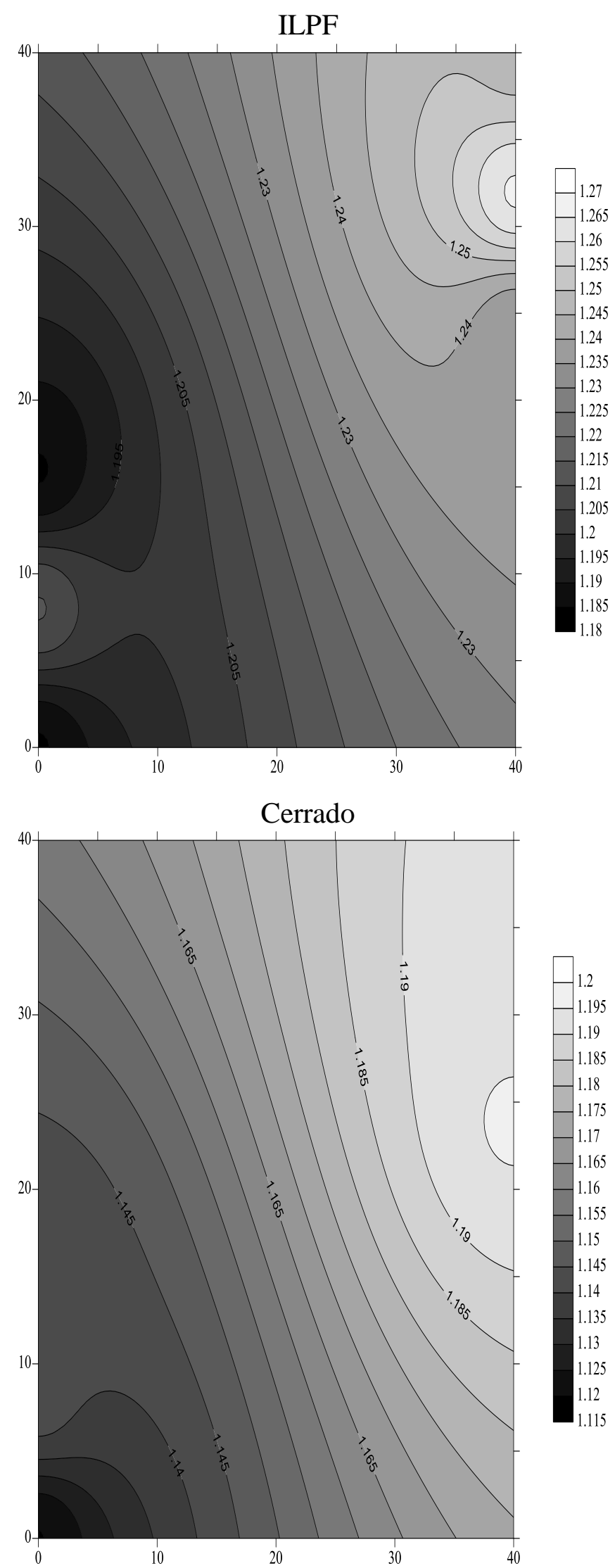

Figura 3. Distribuição espacial da variável estudada (Ds) Densidade do solo $\left(\mathrm{g} \mathrm{cm}^{-3}\right)$ do Latossolo Vermelho distroférrico em função de diferentes usos do solo. 
De modo geral, nas áreas de C. Anuais, Cerrado, e ILPF os maiores valores de Dp concentram-se na camadas mais superficiais do solo, sendo que na área de $\mathrm{C}$. Anuais a camada de solo $5-10 \mathrm{~cm}$ corresponde a $11,2 \%$ maior com relação a profundidade média de 20 - 30 $\mathrm{cm}$, onde obteve-se a maior Dp. No Cerrado há uma diferença positiva, nas camadas $1 \mathrm{~cm}$ e 25 $\mathrm{cm}$ do solo de $2,85 \%$ na $\mathrm{Dp}$, em relação a profundidade de $30-40 \mathrm{~cm}$. Na área de ILPF a maior Dp ocorreu apenas na camada de $1 \mathrm{~cm}$, sendo que os menores valores encontram-se entre: $5-10 \mathrm{~cm}$ e $20-40 \mathrm{~cm}$. Com relação a área da Cana, observa-se que as menores Dp concentram-se entre $0-15 \mathrm{~cm}$, sendo que na camada de $25 \mathrm{~cm}$, a Dp encontrada é 5,5\% maior comparada à profundidade de $10 \mathrm{~cm}$ (Figura 4).

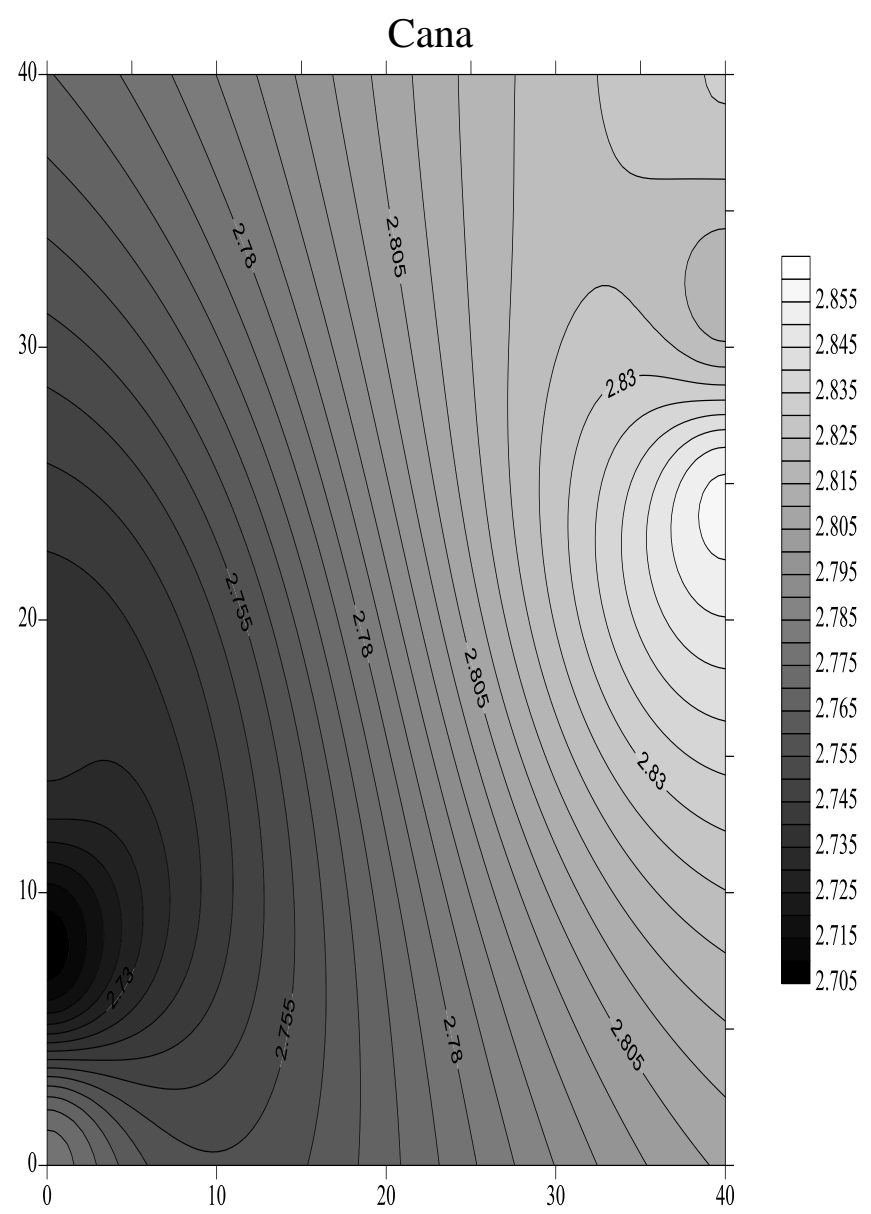

C. Anuais

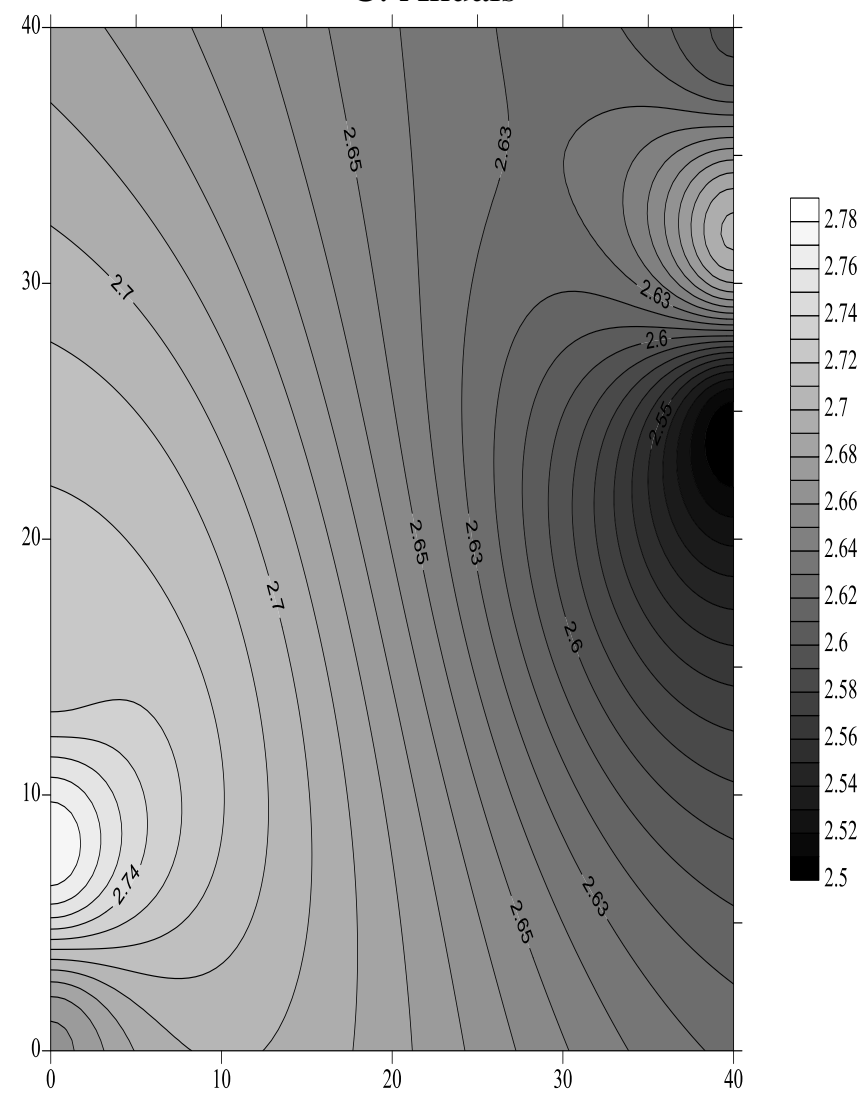

ILPF

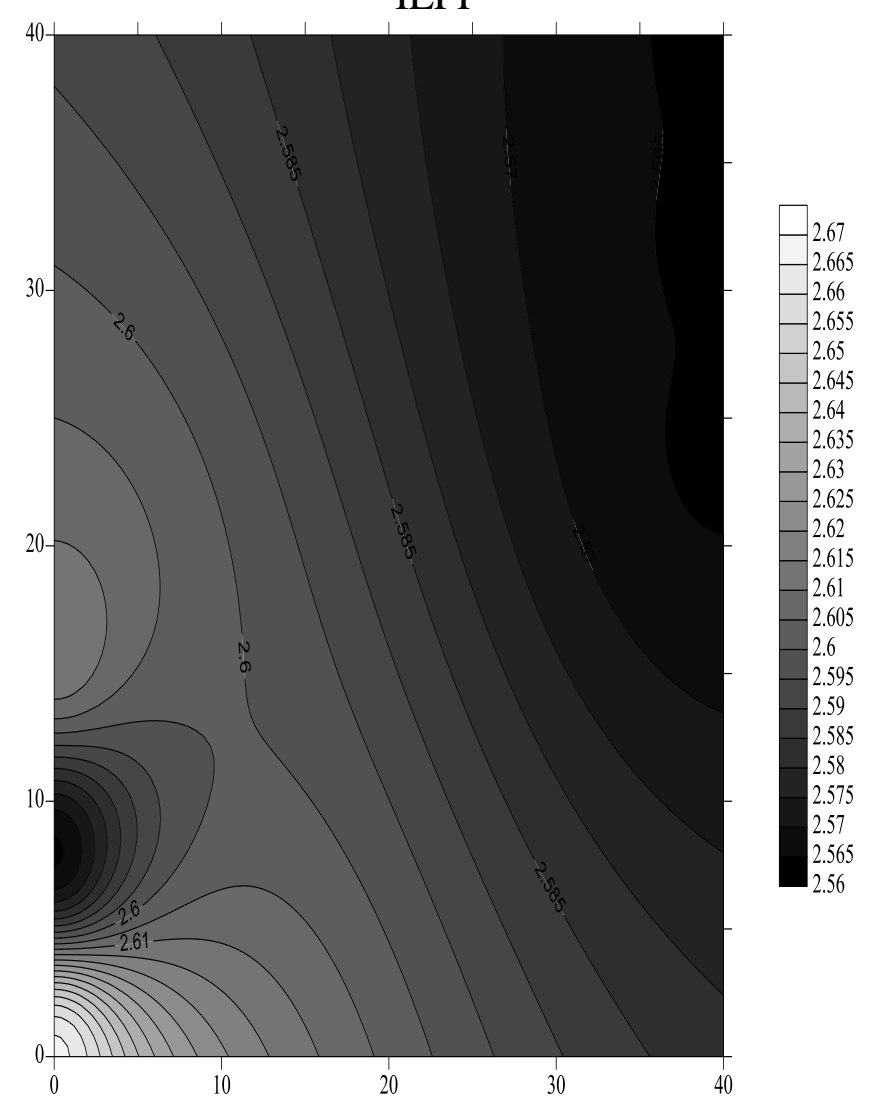


Silva et al.

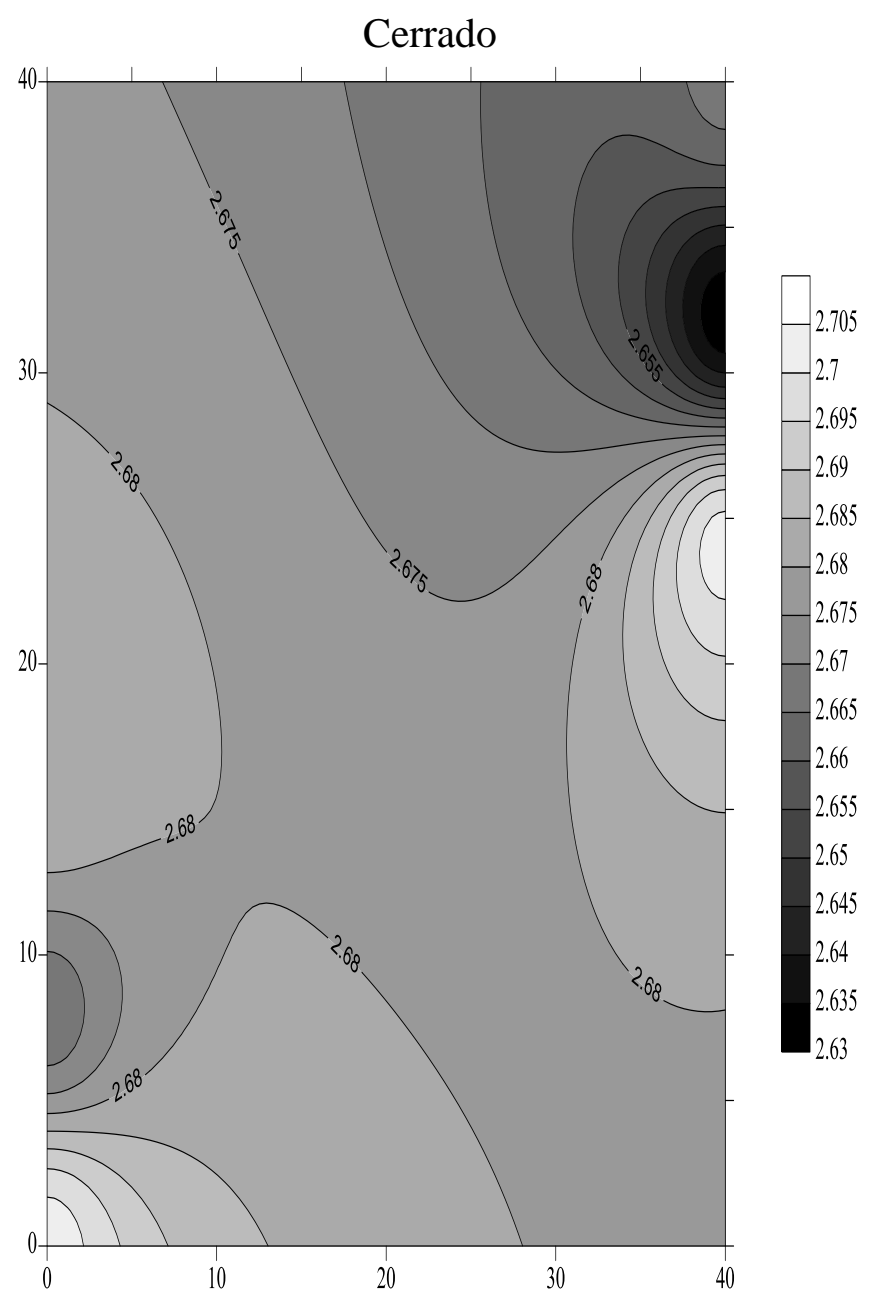

Figura 4. Distribuição espacial da variável estudada (Dp) Densidade de partículas $\left(\mathrm{g} \mathrm{cm}^{-3}\right)$ do Latossolo Vermelho distroférrico em função de diferentes usos do solo.

Nas áreas de C. Anuais, ILPF e Cerrado as camadas superficiais do solo, entre $0-10 \mathrm{~cm}$ apresentaram em média as maiores PT, sendo que ocorreu um decréscimo de 17,7\% (20 - 30 $\mathrm{cm}) ; 9,5 \%(30-35 \mathrm{~cm})$ e $7,3 \%(30-35 \mathrm{~cm})$, respectivamente, com relação a maior PT nas camadas de solo: $5-10 \mathrm{~cm}$, e $0-2 \mathrm{~cm}$ para ILPF e Cerrado. O inverso ocorre na área da Cana, onde na camada $0-25 \mathrm{~cm}$ concentram-se os maiores valores médios de PT, sendo que nas profundidades $1 \mathrm{~cm}$ e $25 \mathrm{~cm}$ a PT é cerca de $11 \%$ menor, com relação à $40 \mathrm{~cm}$ do solo (Figura $5)$.

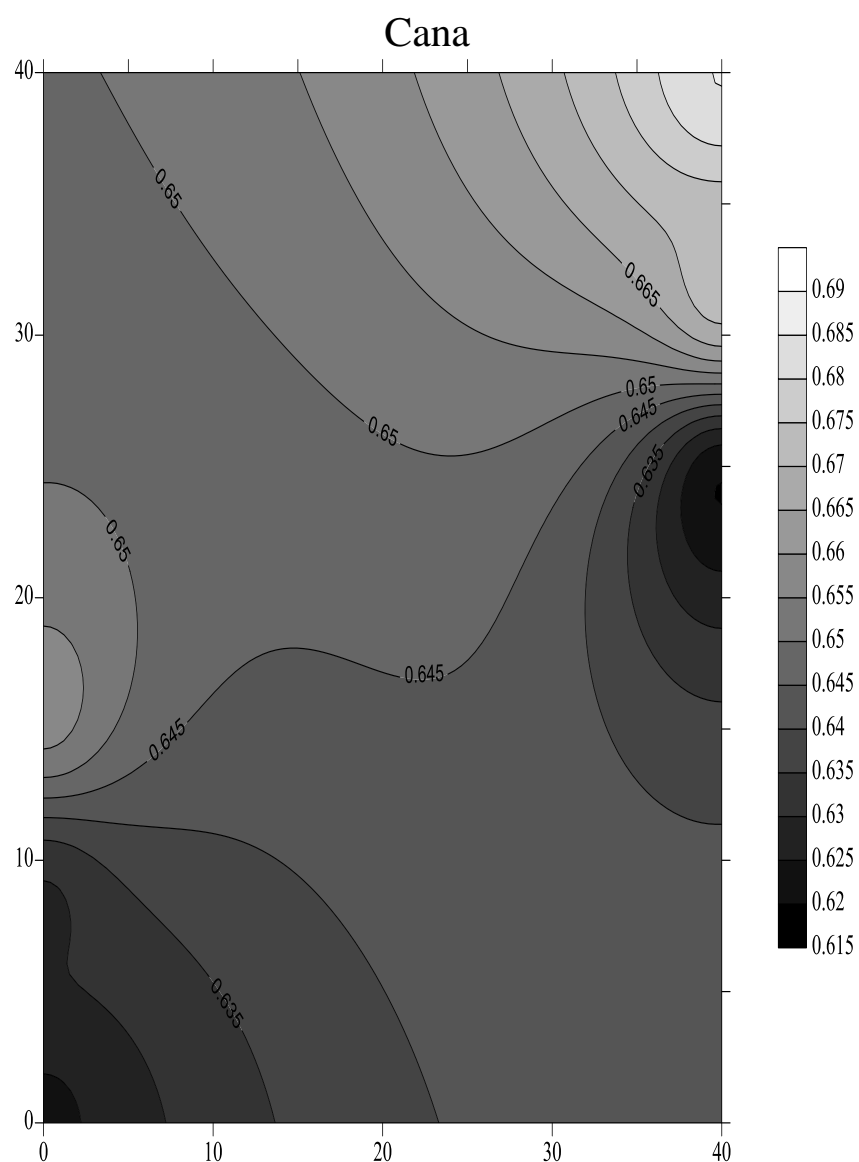

C. Anuais

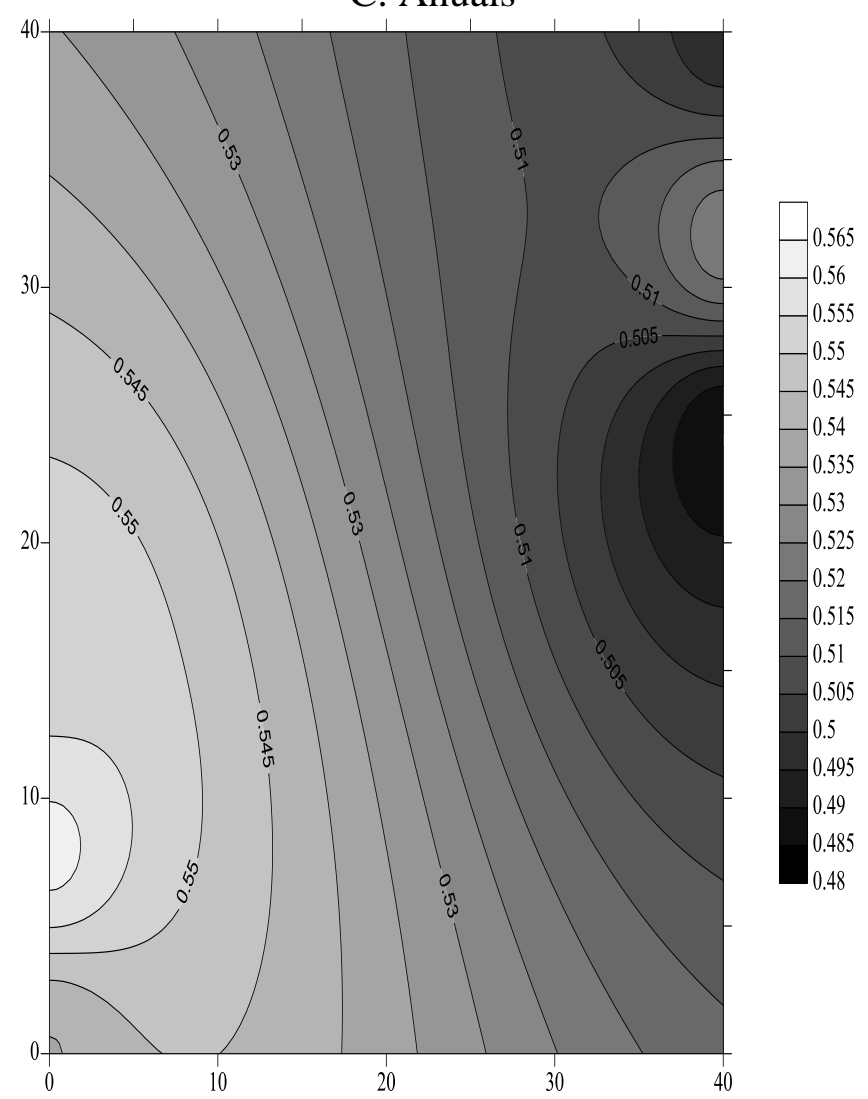



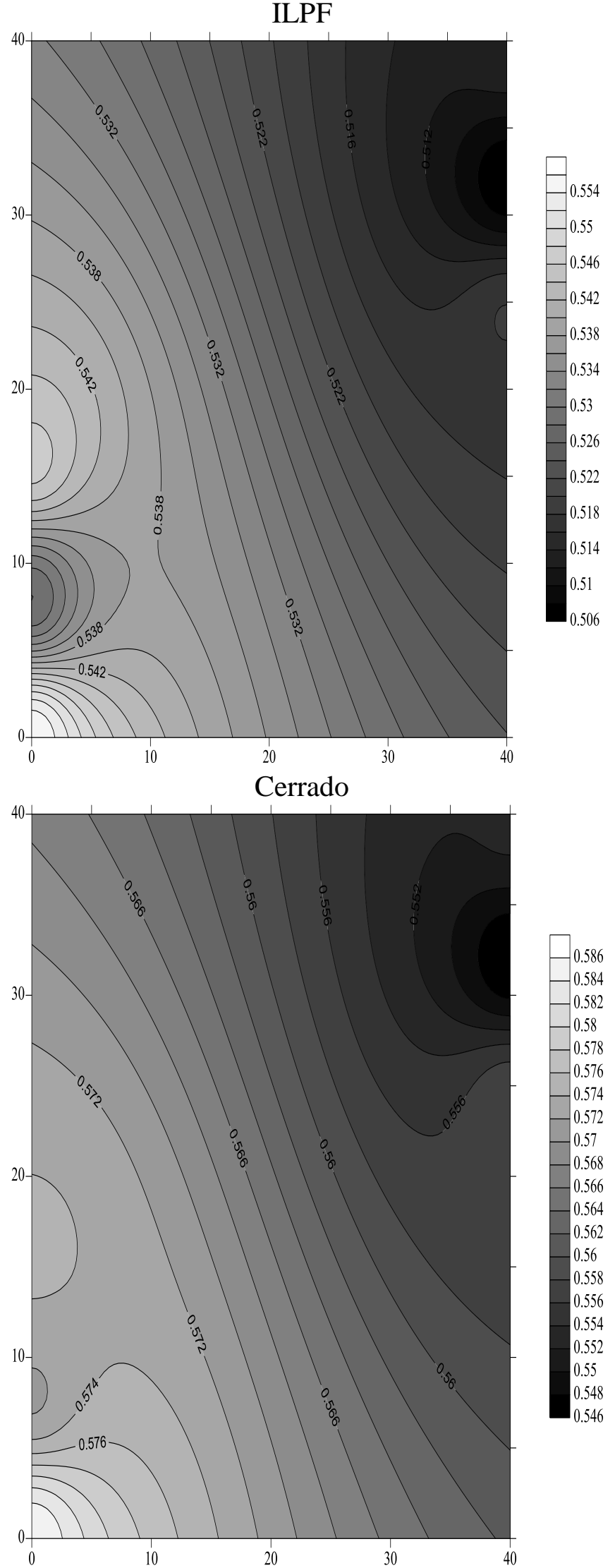

Figura 5. Distribuição espacial da variável estudada (PT) Porosidade Total (\%)do Latossolo
Vermelho distroférrico em função de diferentes usos do solo.

O que se refere a Macro as áreas da Cana e ILPF apresentaram valores médios menores nas camadas superficiais do solo, sendo que nas camadas de $0-5 \mathrm{~cm}$ e $5-10 \mathrm{~cm}$ apresentam decréscimo de $76 \%$ e $82,8 \%$ com relação aos maiores valores de macroporosidade nas camdas de $20-25 \mathrm{~cm}$ e $40 \mathrm{~cm}$ respectivamente. Com relação as áreas de C. Anuais e Cerrado a maior porcentagem de macro poros é encontrada nas camadas mais superficiais do solo, sendo respectivamente $243 \%$ e $163 \%$ maiores em relação as profundidades de $40 \mathrm{~cm}$ e $25 \mathrm{~cm}$, sendo que no Cerrado apenas a camada $0-5 \mathrm{~cm}$ apresenta valores médios altos (Figura 6).

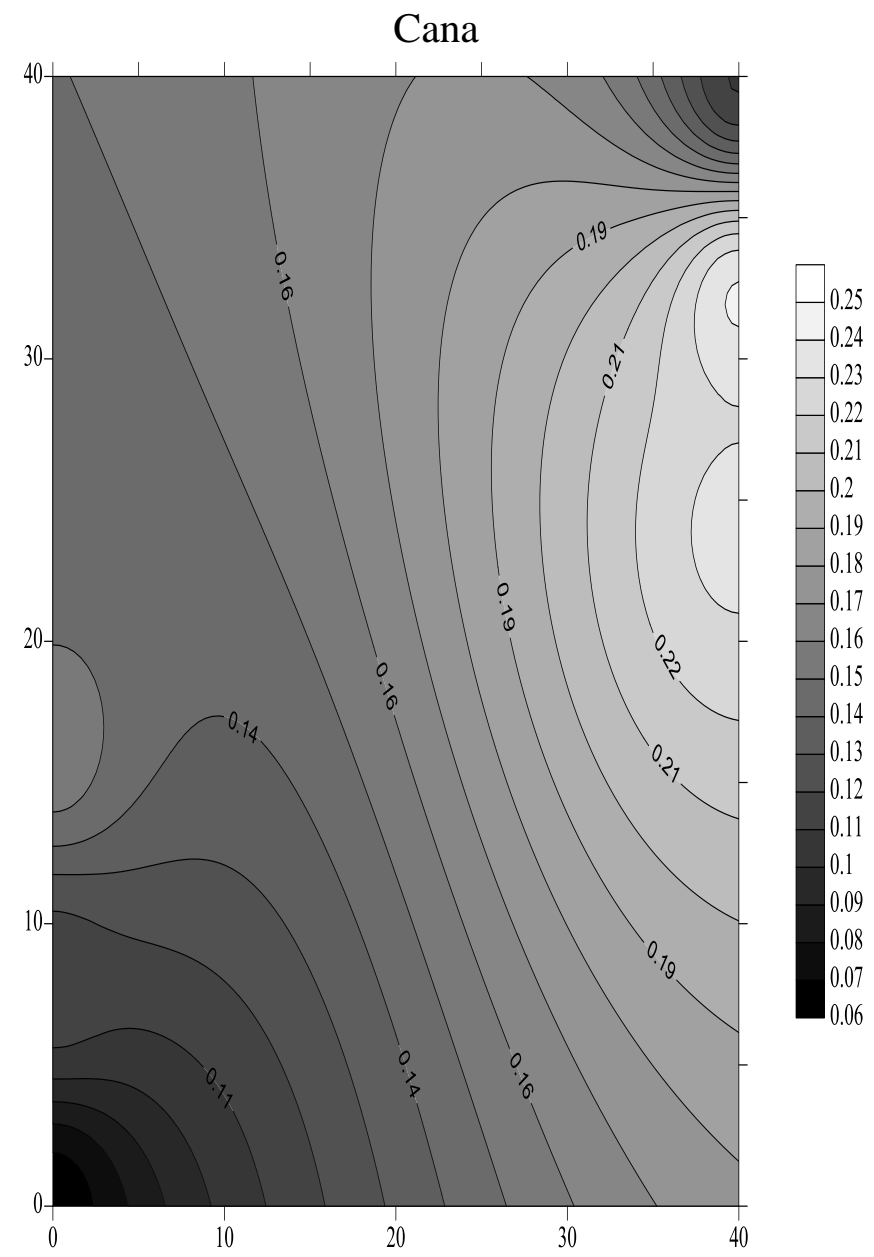


Silva et al.
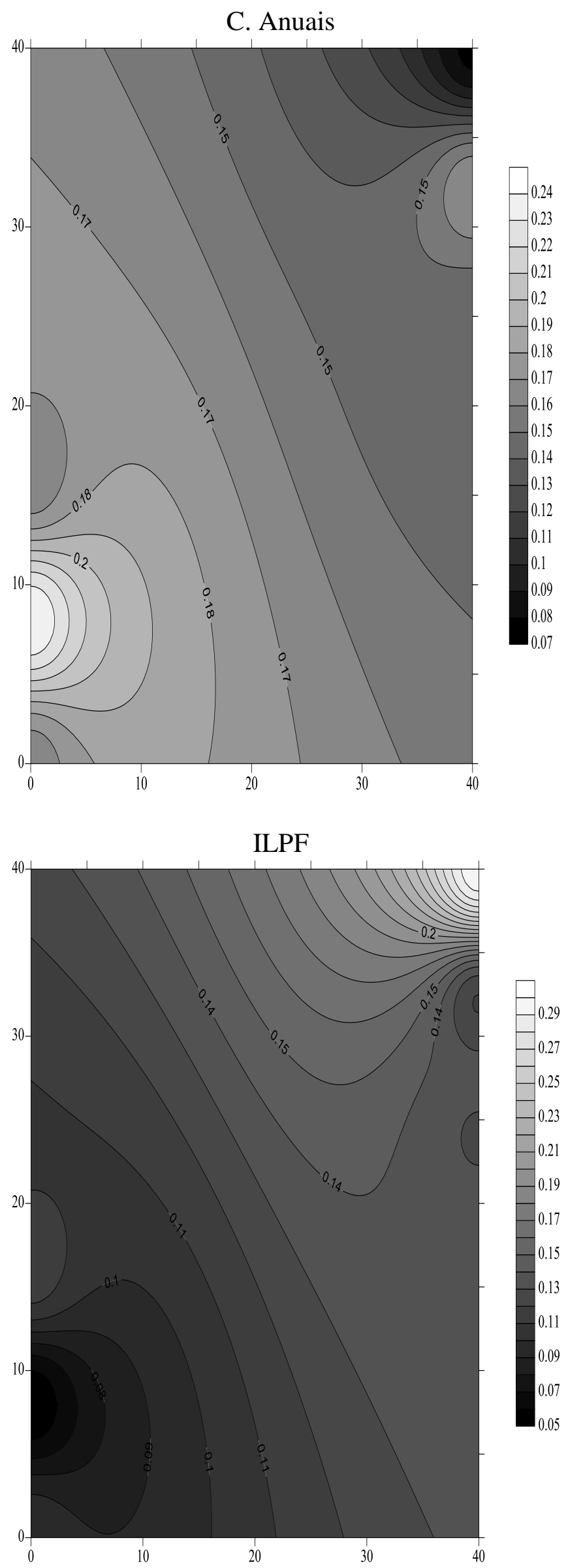

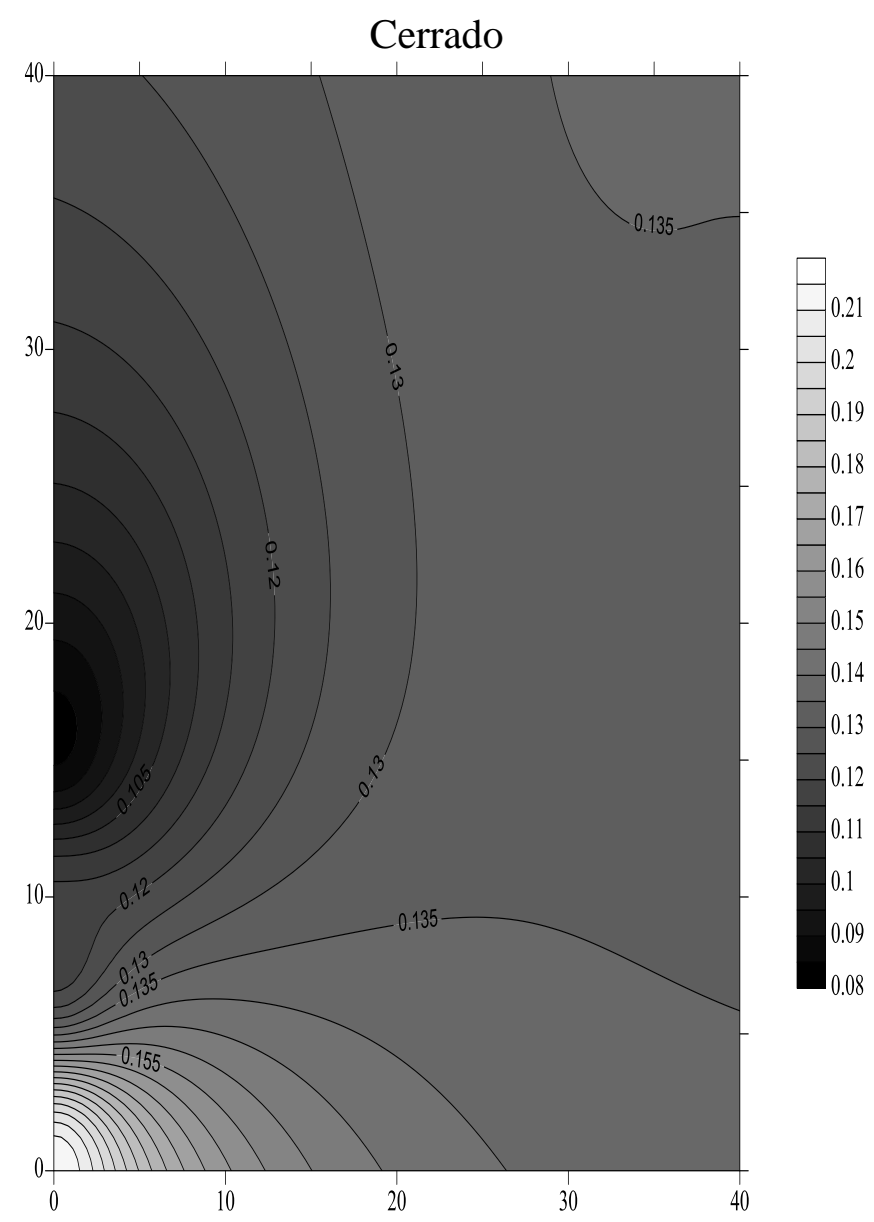

Figura 6. Distribuição espacial da variável estudada Macroporosidade (\%) do Latossolo Vermelho distroférrico em função de diferentes usos do solo.

A maior porcentagem de micro poros se concentraram na camada $0-30 \mathrm{~cm}$ na área de ILPF, sendo $124 \%$ em relação a profundidade de $40 \mathrm{~cm}$; na Cana a microporosidade é cerca de $53 \%$ maior na camada $0-5 \mathrm{~cm}$ e profundidade $40 \mathrm{~cm}$ do solo, em relação a menor porcentagem encontrada. Nas áreas de $\mathrm{C}$. Anuais e Cerrado as profundidade 8 e $1 \mathrm{~cm}$ do solo possuem cerca de $25 \%$ e $24 \%$ menos micro poros em relação as maiores concentrações nas profundidades 40 e $15 \mathrm{~cm}$, onde de modo geral as camadas mais superficiais concentram as menores quantidades de micro poros (Figura 7). 

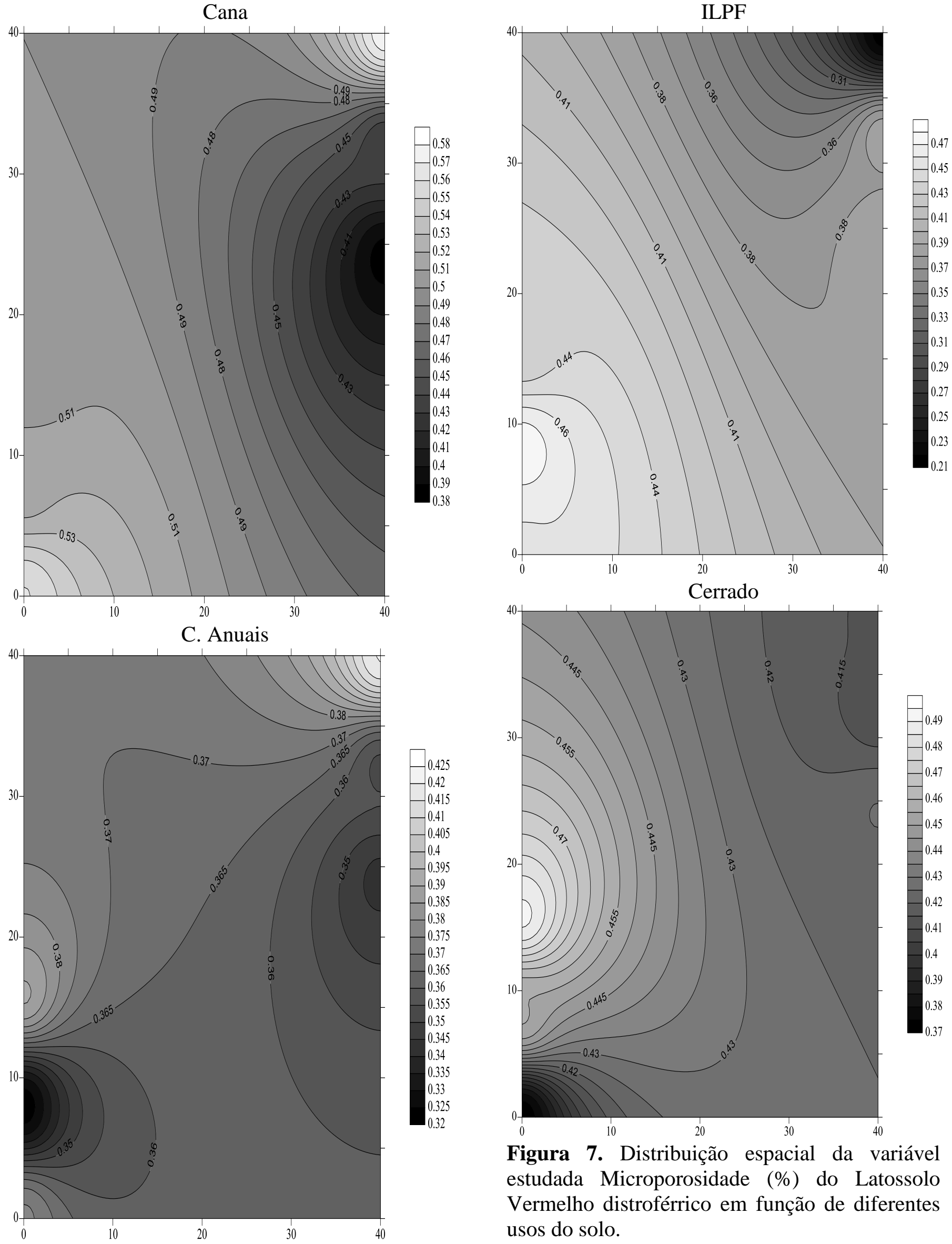

Figura 7. Distribuição espacial da variável estudada Microporosidade (\%) do Latossolo Vermelho distroférrico em função de diferentes usos do solo. 
Como pode se ver na área de Cana, onde prevalece o plantio direto durante 3 anos, há maiores valores de densidade e Micro, e menores de Macro e PT na camada superficial do solo, pelo fato da pressão aplicada pelo transito de máquinas agrícolas (solos argilosos e auto teor de umidade) e a não mobilização do solo (SIQUEIRA, 2006).

Segundo Lanzanova et al. (2007) a redução da macroporosidade na camada superficial na área de ILPF (Figura 8), com relação à encontrada na área de Cerrado, pode ser explicada pelo pisoteio animal, que por consequente acarreta na redução da taxa de infiltração básica (Figura 4), porém não houve acréscimo da densidade na camada superficial do solo.

Os maiores valores de PT na camada superficial do solo $(0-10 \mathrm{~cm})$ na área de Cerrado, conforme afirmam Gonçalves et al. (2012) em seu estudo na cidade de Botucatu UNESP, com relação a infiltração e porosidade do solo, é devido ao acúmulo de matéria orgânica, que é de evidente abundancia em área de mata nativa.

Evidencia-se, através da análise dos resultados, a interferência de alguns atributos do solo na magnitude da taxa de infiltração estável, especialmente a Macro, Ds e a PT. A Cana e a ILPF proporcionou condições mais favoráveis à infiltração de água no solo, considerando a maior intensidade de infiltração de água, sobretudo pela quantidade de palha existente na superfície do solo associada com o seu desenvolvimento radicular, o que reduz o problema relativo ao selamento superficial.

\section{CONCLUSÃO}

As características físicas do solo estão diretamente ligadas a sua capacidade de infiltração de agua, porém o sistema manejado com Cana obteve as condições de solo favoráveis principalmente em relação a Ds, Dp, PT e Macro de 0 a $20 \mathrm{~cm}$ e PT de 20 a $40 \mathrm{~cm}$.

Devido ao processo de mecanização é necessário analisar camadas profundas que correspondam a todo perfil explorado pelas raízes para obter uma maior certeza de disponibilidade de agua para os cultivos.

$\mathrm{O}$ cerrado por manter as suas caracterizas do solo, apresentou o melhor valor infiltração de $\left(56,89 \mathrm{~cm} \mathrm{~h}^{-1}\right)$.

Dentro dos sistemas manejados, quanto mais profundo foi o processo de preparo do solo aliado em seguida a um processo de "descanso" durante o desenvolvimento de espécies perenes, mesmo com ação de compactação por pisoteio e tráfico de máquinas, maior foi a capacidade de infiltração de água neste solo, nas condições expostas no trabalho.

\section{AGRADECIMENTOS}

Os autores agradecem ao Ministério da Ciência e Tecnologia (MCT), ao Conselho Nacional de Desenvolvimento Científico e Tecnológico (CNPq) e à Coordenação de Aperfeiçoamento de Pessoal de Nível Superior (Capes) pelo apoio financeiro e estrutural.

\section{REFERÊNCIAS BIBLIOGRÁFICAS}

ALVES, M. C.; SUZUKI, L. G. A. S.; SUZUKI, L. E. A. S. Densidade do solo e infiltração de água como indicadores da qualidade física de um Latossolo Vermelho distrófico em recuperação. Revista Brasileira de Ciência do Solo, v.31, p.617-625, 2007.

ALVES SOBRINHO, T.; VITORINO, A.C.T.; SOUZA, L.C.F.; GONÇALVES, M.C.; 
CARVALHO, D.F. Infiltração de água no solo em sistemas de plantio direto e convencional. Revista Brasileira de Engenharia Agrícola e Ambiental, Campina Grande, v.7, n.2, p.191-196, 2003.

ARVIDSSON, J. Subsoil compaction caused by heavy sugarbeet harvestes in Southern Sweden I. Soil physical properties and crop yield in six field experiments. Soil Till. Res., 60:67-78, 2001.

BARCELOS, A. A.; CASSOL, E. A.; DENARDIN, J. E. Infiltração de água em um Latossolo Vermelho-Escuro sob condições de chuva intensa em diferentes sistemas de manejo. Revista Brasileira de Ciência do Solo, ViçosaMG, v.23, N.1, p.35-43, 1999.

BERNARDO, S. Manual de Irrigação, 6 ed. Viçosa: UFV. Imprensa Universitária, 2002, $596 p$.

BERNARDO, S.; SOARES, A. A.; MANTOVANI, E. C. Manual de irrigação. ed. 8. Viçosa: UFV, 2006. 625p.

BLAKE， G. R.; HARTGE, K. H. Particle density. In: KLUTE, A. (Ed.). Methods of soil analysis. 2. ed. Madison: ASA/SSSA, 1986. p. 377-382. (Agronomy monograph, 9).

EMBRAPA - EMPRESA BRASILEIRA DE PESQUISA AGROPECUÁRIA. Manual de métodos de análises de solo. 2.ed. Rio de Janeiro: Ministério da Agricultura e do abastecimento, 1997. 212p.

EMBRAPA - EMPRESA BRASILEIRA DE PESQUISA AGROPECUÁRIA. Sistema brasileiro de classificação de solos. 2.ed. Rio de Janeiro: Ministério da Agricultura e do abastecimento, 2006. 306p.
GONÇALVES， F. C.; MORAES, M. H. Porosidade e infiltração de água do solo sob diferentes sistemas de manejo. Irriga, Botucatu, v.17, n.3, p.337-345, julho - setembro, 2012.

GOLDEN SOFTWARE. Surfer for Windows version 8.0. Colorado: Golden, 2002.

JOSÉ, J. V.; REZENDE, R.; MARQUES, P. A. A.; GONÇALVES, A. C. A.; SOUZA, R. S.Variabilidade espacial de variáveis físicohídricas de dois latossolos da região noroeste do estado do Paraná. Irriga, Botucatu, v. 17, n. 2, p. 208 - 219, abril-junho, 2012.

LANZANOVA, M.E.; NICOLOSO, R. da S.; LOVATO, T.; ELTZ, F.L.F.; AMADO, T.J.C.; REINERT, D.J. Atributos físicos do solo em sistema de integração lavoura-pecuária sob plantio direto. Revista Brasileira de Ciência do Solo, v.31, p.1131-1140, 2007.

PAIXÃO, F.J.R.; ANDRADE， A.R.S.; AZEVEDO, C.A.V.; COSTA, T.L.; GUERRA, H.O.C. Ajuste da curva de infiltração por meio de diferentes modelos empíricos. Pesquisa aplicada \& Agrotecnologia, Guarapuava, v.2, n.1, p.108-112, 2009.

PANACHUKI, E.; ALVES SOBRINHO, T.; VITORINO, A.C.T.; CARVALHO, D.F.; URCHEI, M.A. Parâmetros físicos do solo e erosão hídrica sob chuva simulada em área de integração agricultura-pecuária. Revista Brasileira de Engenharia Agrícola e Ambiental, Campina Grande, v.10, n.2, p.261268, 2006.

PANACHUKI, E. Infiltração de água no solo e erosão hídrica, sob chuva simulada, em sistema de integração agricultura-pecuária. Dourados, Universidade Federal da Grande Dourados, 2003. 67p. (Dissertação de Mestrado). 
PANACHUKI, E. Rugosidade superficial do solo e índices relacionados, sob diferentes sistemas de manejo. Dourados, Universidade Federal da Grande Dourados, 2008. 143p. (Tese de Doutorado).

PEREIRA, V. R.; TEIXEIRA FILHO, T. Identificação das áreas susceptíveis aos processos erosivos em duas bacias do Sistema Cantareira por meio de diferentes cenários. Acta Scientiarum Agronomy, v. 31, n. 1, p.155- 163, 2009.

PRANDO, M. B.; OLIBONE, D.; OLIBONE, A. P. E.; ROSOLEM, C. A. Infiltração de água no solo sob escarificação e rotação de culturas. Revista Brasileira Ciência do Solo, vol.34, n.3, pp. 693-700. 2010.

SOUZA, Z.M. \& ALVES, M.C. Propriedades físicas e teor de matéria orgânica em um Latossolo Vermelho de cerrado sob diferentes usos e manejos. Acta Scientiarum, 25:27-34, 2003.
SOUZA, Z. M.; BEUTLER, A. N.; PRADO, R. M.; BENTO, M. J. C. Efeito de sistemas de colheita de cana-de-açúcar nos atributos físicos de um Latossolo Vermelho. Científica, Jaboticabal, v.34, n.1, p.31-38, 2006.

SIQUEIRA, G. M. Atributos físicos do solo em sistema de integração lavoura-pecuária sob plantio direto. Disertação de Mestrado Instituto Agronômico de Pós-Graduação (IAC), 2006.

VOMOCIL, J.A.; FLOKER, W.J. Effect of soil compaction on storage and moviment $f$ soil, air and water. Transactions of the ASAE, v.4, p.242-246, 1961.

VOMOCIL, J. A. Porosity. In: BLACK, C.A., ed. Methods of soil analysis. Madison, American Society of Agronomy, Soil Science Society of America, 1965. pt.1. p.299-314. (Agronomy Monography, 9). 